\title{
Salivary Gland Stone
}

National Cancer Institute

\section{Source}

National Cancer Institute. Salivary Gland Stone. NCI Thesaurus. Code C34994.

A concretion in the salivary gland. 